\title{
Identificação do potencial de contaminação de aquíferos livres por vinhaça na bacia do Ribeirão do Pântano, Descalvado (SP), Brasil
}

\author{
Cássia de Ávila Ribeiro Junqueira', Vitor Eduardo Molina Junior ${ }^{1}$, Luiz Fernando Lossardo', \\ Bruna da Cunha Felicio ${ }^{I}$, Orlando Moreira Junior ${ }^{l}$, Regina Célia Foschini, \\ Rodolfo Moreda Mendes ${ }^{2}$ \& Reinaldo Lorandi ${ }^{3}$
}

\begin{abstract}
Resumo Este trabalho tem o objetivo de identificar o potencial de contaminação de aquíferos livres na região da Bacia Hidrográfica do Ribeirão do Pântano (BHRP), no município de Descalvado/SP, causado pela utilização da vinhaça aplicada diretamente no solo através da técnica de fertirrigação na cultura de cana-de-açúcar. A vinhaça, apesar de possuir muitos atributos positivos para o solo, é um elemento com alto poder poluente, estimado em cerca de cem vezes maior que o do esgoto doméstico. Neste sentido, o artigo visa a aplicar um procedimento metodológico para elaboração de uma carta de potencial de contaminação dos aquíferos livres por vinhaça, realizado em função da análise dos componentes e atributos do meio físico da região estudada, organizado em um ambiente de Sistema de Informações Geográficas (SIG). Os resultados obtidos neste trabalho apontaram que a maioria das áreas onde ocorre o cultivo de cana-de-açúcar, e em que supostamente acontece aplicação da vinhaça no solo, localiza-se em regiões com altos potenciais de contaminação dos aquíferos livres.
\end{abstract}

Palavras-chave: contaminação por vinhaça, aquíferos livres, bacia do Ribeirão do Pântano, Sistemas de Informações Geográficas (SIG).

\begin{abstract}
Identification of the contamination potential of free aquifers by vinasse in the Ribeirão do Pântano drainage basin in Descalvado (SP), Brazil. The work reported here involved the identification of the contamination potential of free aquifers in the region of the Ribeirão do Pântano Drainage Basin (RPDB) in the municipality of Descalvado, state of São Paulo, Brazil, resulting from the direct application of vinasse on soil through the fertirrigation technique used in sugarcane cultivation. Although it offers many positive attributes for the soil, vinasse is a highly polluting element, with a pollutant effect estimated to be 100 -fold higher than that of domestic sewage. This paper, therefore, reports on the application of a methodological procedure for mapping the potential contamination of free aquifers by vinasse, based on the analysis of the components and attributes of the physical environment of the region under study, and organized in a geographic information system (GIS) environment. The results obtained in this study indicate that most of the areas that are under sugarcane cultivation, and where vinasse is presumably applied to the soil, are areas with high potential for contamination of free aquifers.
\end{abstract}

keywords: contamination by vinasse, free aquifers, Ribeirão do Pântano drainage basin, Geographic Information Systems (GIS).

INTRODUÇÃO O crescimento populacional do nosso planeta e a necessidade por energia para a indústria e o comércio têm aumentado gradativamente, e as reservas de petróleo, principal fonte de energia do modelo de desenvolvimento atual, estão chegando ao fim. Aliado a estes fatores o aquecimento global, provocado pela emissão de gases do efeito estufa, é ainda um agravante à procura de soluções. Assim, várias instituições de pesquisa e ensino estão trabalhando em busca de outras fontes de energia, de preferência, renováveis. Uma das alternativas de uso de energia limpa que é sucesso no Brasil é o álcool, um biocombustível produzido a partir da cana-de-açúcar.

No processo de fabricação do álcool extrai-se um subproduto muito rico em nutrientes: a vinhaça. A grande vantagem no emprego da vinhaça no solo, por meio de fertirrigação, é que ela pode substituir em grande parte os nutrientes da adubação mineral, sendo que vários trabalhos mostram aumento de produtividade da cana-de-açúcar devido à sua aplicação.

O benefício imediato decorrente do uso racional desse resíduo nas lavouras canavieiras se dá pelo aumento da produtividade, que ocorre com mais intensidade em solos mais pobres e em regiões mais secas, e inclui-se aqui a economia de fertilizantes. Entretanto, mesmo com os efeitos benéficos da vinhaça no solo sabe-se que, quando aplicada em altas taxas, conduz a efeitos indesejáveis, como o comprometimento da qualidade da cana para produção de açúcar, poluição do

1 - UFSCAR, Universidade Federal de São Carlo, Programa de Pós-graduação em Engenharia Urbana - PPGEU, São Carlos (SP), Brasil.

E-mails: carjunqueira@yahoo.com.br, molinavitor@yahoo.com.br, llossardo@hotmail.com,br_fel@yahoo.com.br,

orlandomoreirajunior@yahoo.com.br, reginafos@yahoo.com.br

2 - Instituto Geológico, São Paulo (SP), Brasil. E-mail: rodolfo.mendes@igeologico.sp.gov.br

3 - UFSCAR, Universidade Federal de São Carlos, São Carlos (SP), Brasil. E-mail: lorandi@ufscar.br 
lençol freático e até para a salinização do solo.

Pode-se considerar também que, de maneira geral, a cada safra o valor de área de fertirrigação das usinas aumenta, mostrando a preocupação das usinas com o uso racional da vinhaça, buscando maior rendimento agrícola e redução no uso de fertilizantes químicos, bem como uma adequação de dose de vinhaça que não cause prejuízo ao meio ambiente.

Entretanto, a expansão das áreas de plantação de cana-de-açúcar, devido à demanda do uso do álcool na matriz energética brasileira e a utilização da vinhaça para a fertirrigação podem acarretar grandes impactos ambientais se não forem realizados em áreas planejadas.

A possibilidade de expansão das áreas de cultivo de cana-de-açúcar em áreas que antes eram destinadas a outras atividades leva a necessidade de estudos da adequabilidade dessas novas áreas em relação ao potencial de contaminação da vinhaça (subproduto da fabricação do álcool) nos aquíferos livres.

Este artigo visa, a partir do estudo das características do meio físico da região da Bacia Hidrográfica do Ribeirão do Pântano (BHRP) localizada no município de Descalvado/SP, a identificar os potenciais de contaminação dos aquíferos livres, causados pela aplicação de vinhaça nas áreas de cultivo de cana-de-açúcar e solo exposto.

O geoprocessamento é uma ferramenta amplamente utilizada nos estudos de impactos no meio físico. Neste trabalho foi utilizado o software SPRING, versão 5.0.1, como Sistema de Informações Geográficas - SIG, para a implantação e manipulação de banco de dados geográficos, e no qual foram comparados dois métodos diferentes para o cruzamento dos dados: o Booleano e o Processo Analítico Hierárquico (AHP).

Caracterização da área de estudo A BHRP é uma subbacia do rio Mogi-Guaçu, que engloba parte dos municípios de Analândia, Descalvado e São Carlos (SP) e localiza-se entre as coordenadas UTM $7552000 \mathrm{mS} / 7596000 \mathrm{mS}$ e $212000 \mathrm{~mW} / 232000 \mathrm{mWGr}$, no datum SAD 69 e fuso 23, perfazendo uma área total com cerca de $393 \mathrm{Km}^{2}$.

A rede de drenagem que constitui a BHRP forma vales mais profundos na região de cabeceira e tende a formar planícies de inundação à medida que se aproxima do rio Mogi-Guaçu. As altimetrias variam entre 540 e $1040 \mathrm{~m}$ compondo um desnível de $500 \mathrm{~m}$ e apresentando variadas formas de relevo como planícies, colinas, morrotes e cuesta, além de áreas cênicas como a cachoeira do Pântano. Segundo Mendonça \& Danni-Oliveira (2007), na região da BHRP predomina o subtipo Clima Tropical Úmido-Seco com um a três meses de seca.

De acordo com Ross e Moroz (1997), a BHRP encontra-se localizada na Bacia Sedimentar do Paraná (morfoestrutura), englobada pelas seguintes unidades morfoesculturais: Planalto Ocidental Paulista (Planalto Residual de São Carlos e Patamares Estruturais de Ribeirão Preto) e Depressão Periférica Paulista (Depressão Mogi-Guaçu). Os tipos de solos predominantes na BHRP são: latossolo roxo, latossolo vermelho escuro, latossolo vermelho amarelo, podzólico vermelho amarelo, terra roxa estruturada, areias quartzozas profun- das, solos litólicos e solos hidromórficos (BRASILEMBRAPA, 1999).

Geologicamente, as unidades litoestratifigráficas aflorantes na BHRP ocorrem nas seguintes características: Quaternário, Formação Santa Rita do Passa Quatro, Formação Itaqueri, Formação Serra Geral e Intrusivas Básicas, Formação Botucatu e Formação Pirambóia.

Em relação à exploração dos recursos hídricos subterrâneos, nota-se que na bacia essa exploração tem ocorrido de modo intenso, sendo que tanto o abastecimento das áreas urbanas quanto o das propriedades rurais têm-se utilizado da perfuração de poços semiartesianos, sem que haja um acompanhamento das condições de utilização e exploração desses recursos (Bertuga-Cerqueira 1999 apud Moreira 2002).

Quanto ao uso do solo, as principais formações vegetais que compõem a região estudada correspondem ao cerrado, à mata mesófila (mata estacional semidecídua) e à mata ciliar, restando apenas alguns remanescentes que se encontram dispersos em manchas relativamente isoladas na região central da matriz de ocupação agropecuária (Fig. 1). A figura 2 mostra a distribuição espacial dos temas cana-de-açúcar e solo exposto nos limites da bacia, destacando apenas as áreas de cultivo de cana-de-açúcar (8222,00 ha, 20,9\%) e das parcelas de solo exposto $(1489,75 \mathrm{ha}, 3,8 \%)$, no qual devido às suas localizações próximas a canaviais, estima-se que estão sendo preparadas para o cultivo de cana-de-açúcar.

Características da vinhaça A vinhaça, principal efluente das destilarias de álcool, também conhecida por restilo, vinhoto ou vinhote, conforme encontrado na literatura clássica, resulta na proporção entre 10 a 18 litros por litro de álcool produzido e sua composição varia em função da natureza da matéria-prima e da operação dos aparelhos de destilação. Pela grande quantidade gerada de vinhaça para a produção do álcool, e aumento da produção deste (Brasil 2007) a disposição final desse líquido residual se constitui, entre outros, em um problema ambiental.

A vinhaça possui valor fertilizante, sendo rico em potássio, cálcio, magnésio, enxofre e micronutrientes (Guagnoni et al. 2003). Ela possui, porém, um alto poder poluente, cerca de cem vezes maior que o do esgoto doméstico (Silva et al. 2007), decorrente do elevado teor de matéria orgânica, baixo $\mathrm{pH}$, elevada corrosividade, altos índices de demanda bioquímica de oxigênio (DBO), em torno de 20.000 a $35.000 \mathrm{mg} / \mathrm{l}$ e elevada temperatura na saída dos destiladores, entre 85 e $90{ }^{\circ} \mathrm{C}$ (Rossetto 1987). É considerada altamente nociva à fauna, flora, microfauna e microflora das águas doces, além de afugentar a fauna marítima que procura a costa para desova. Possui ainda problemas de insalubridade, como mau cheiro devido à formação de gases decorrentes da decomposição anaeróbia, além de agravar o problema da malária, por eliminação de peixes larvófagos e aumento na quantidade de pernilongos, e também contribui para o aparecimento de endemias, como a amebíase e a esquistossomose (Cruz 1991).

Até a década de 1970, segundo Cruz (op. cit.) 
Uso e Ocupaçẩo do Solo - 2006

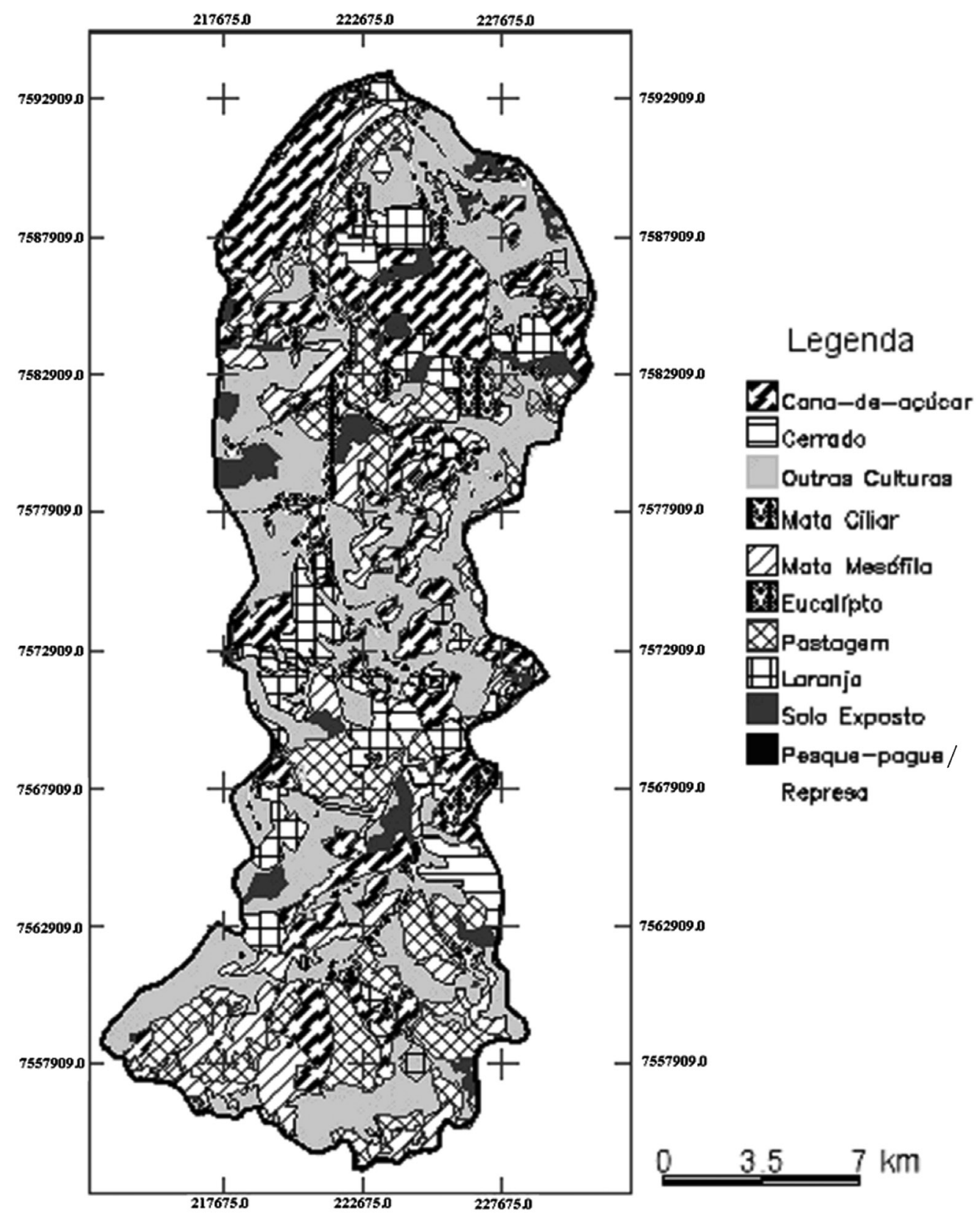

Figura 1 - Mapa do Uso do Solo da BHRP.

\& Casarini (2008), o principal destino da vinhaça era o lançamento in natura em corpos d'água, causando a mortandade de peixes e outros organismos aquáticos. Este fato se agravou com a criação do Pró-álcool em 1975, havendo um aumento na produção do álcool e conseqüentemente da vinhaça, agravando ainda mais a poluição dos recursos hídricos.

Em razão desse impacto mais visível, essa forma de disposição do resíduo foi proibida pelas portarias $\mathrm{n}^{\mathrm{o}} 323$, de 29 de novembro de 1978 , e $\mathrm{n}^{\mathrm{o}} 158$, de 03 de novembro de 1980 , do extinto Ministério do Interior, obrigando as indústrias a optarem por outras formas de des- carte.

A partir dessa proibição, a disposição da vinhaça passou a ser geralmente efetuada no solo, na maioria das vezes por fertirrigação, através de caminhõestanque e sistemas de irrigação por aspersão e sulcos de infiltração (Vieira 1986). Assim, após o surgimento do Pró-álcool a aplicação da vinhaça diretamente no solo se intensificou, pois o álcool passou a ser produzido em grande escala, gerando maiores quantidades do resíduo (Brito \& Rolin 2005).

Em muitos casos essa forma de disposição da vinhaça ocorreu sem critérios definidos, causando im- 


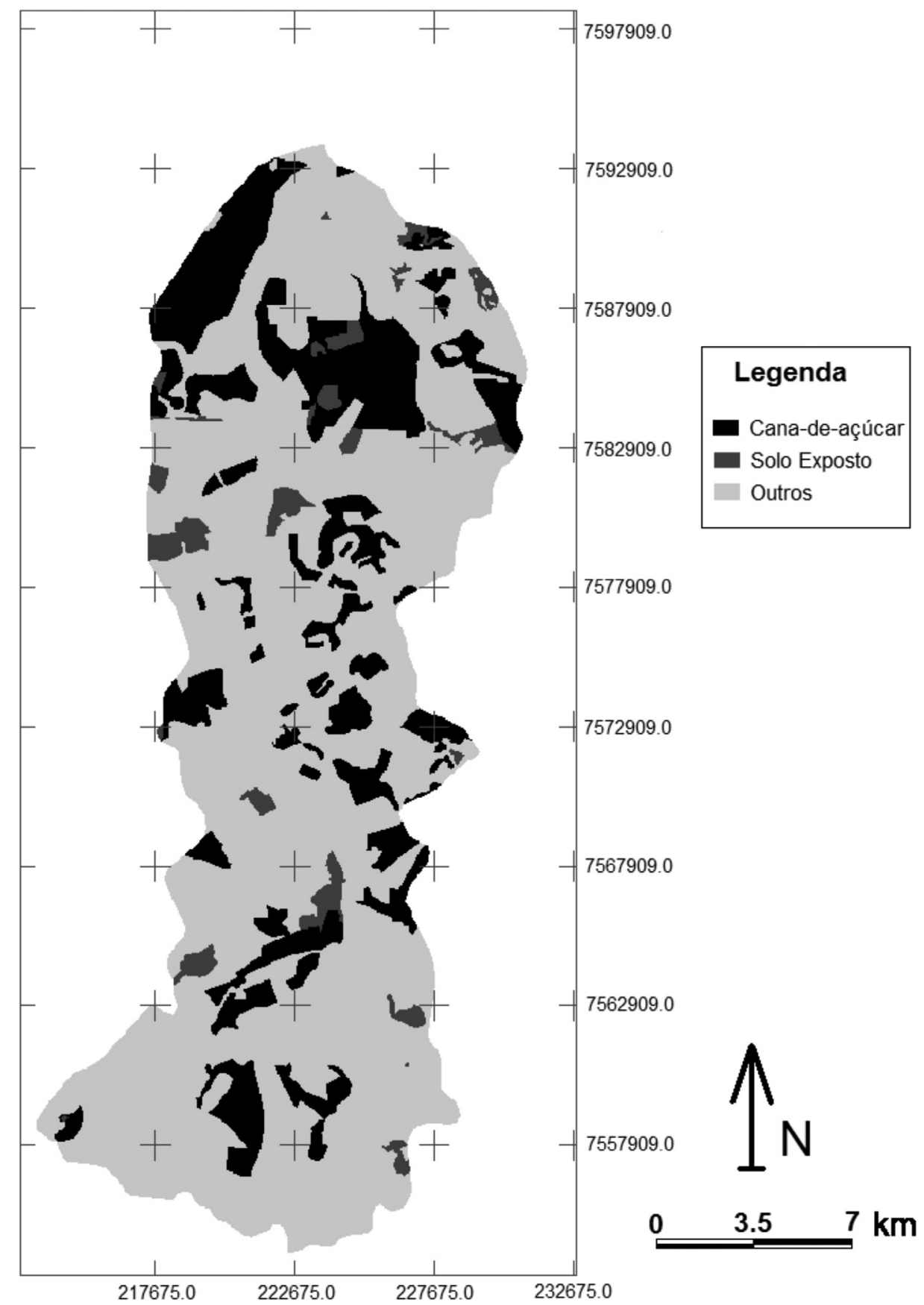

Figura 2 - Mapa das áreas com atividades de cultivo de cana-de-açúcar e solos expostos.

pactos na qualidade do solo e das águas subterrâneas. Estudos sobre a poluição gerada por esse resíduo só foram desenvolvidos a partir da década de 80 , pois até então apenas os benefícios da vinhaça na fertirrigação eram comentados.

A respeito dessa prática de destinação da vinhaça, o estado de São Paulo, por meio da Companhia de Tecnologia de Saneamento Ambiental (CETESB), editou, em dezembro de 2006, a Norma Técnica P4.231 (São Paulo 2006) que tem por objetivo estabelecer os critérios e procedimentos para o armazenamento, transporte e aplicação da vinhaça em solo agrícola.
Esta norma prevê que seja feito anualmente um Plano de Aplicação da Vinhaça, onde são exigidas a caracterização dos dados físicos e a quantificação das taxas indicativas de dosagem a serem aplicadas. Entretanto, nesta norma não foi previsto um estudo do potencial de contaminação de aquíferos, este estudo facilitaria os locais de implantação de poços para o monitoramento da percolação do fluido referido, identificando preferencialmente nos locais onde há maior probabilidade de alteração da qualidade.

Vários autores, entre eles Cunha et al. (1981), salientam a condução de vários estudos sobre a disposi- 
ção da vinhaça no solo. Esses estudos enfocam principalmente os efeitos no $\mathrm{pH}$ do solo, propriedades físicoquímicas e seus efeitos na cultura da cana-de-açúcar, mas poucos avaliaram o real potencial poluidor da vinhaça sobre o solo e o lençol freático.

Lyra et al. (2003) aludem que a aplicação de vinhaça na fertirrigação de canaviais minimiza o potencial poluidor do resíduo, porém, nas condições de seus estudos, essa minimização não garantiu o atendimento a todos os parâmetros de qualidade exigidos pelo Conselho Nacional do Meio Ambiente (Brasil 2005), afetando a qualidade da água do lençol freático.

A aplicação de altas taxas de vinhaça no solo conduz a efeitos indesejáveis, como o comprometimento da qualidade da cana para produção de açúcar, poluição do lençol freático e salinização do solo. Nesse cenário, alguns estudos, entre eles o de Ribas et al. (2008), buscam melhores formas de disposição do resíduo em solo agrícola, através de seu tratamento prévio.

Embora ainda haja limitação na bibliografia sobre os efeitos da vinhaça no solo e nas águas subterrâneas, os autores Silva et al. (2007) afirmam que é possível verificar que os resultados são bastante variáveis em razão da grande diversidade de solos e composição das vinhaças. Os autores verificaram também que as chances de contaminação de águas subterrâneas pela vinhaça devem estar relacionadas ao tipo e condições do solo local, além da profundidade do lençol freático, proximidade de nascentes e intensidade da atividade vegetal na área.

Assim, seguindo o procedimento metodológico deste trabalho, a avaliação do potencial à contaminação do aquífero livre por vinhaça deverá ser realizada em função dos componentes ambientais, material inconsolidado, substrato rochoso, água e relevo da área estudada.

MATERIAIS E MÉTODOS A metodologia utilizada para a elaboração da carta de contaminação dos aquíferos livres por vinhaça foi adaptada de Zuquette \& Gandolfi (2004), os quais propuseram uma metodologia para a elaboração da carta de potencial de risco à contaminação das águas subterrâneas por fertilizantes. Fazendo uma analogia entre fertilizantes e vinhaça foi possível o ordenamento das áreas, categorizando sua potencialidade como pertencente às classes de potencial: baixo, intermediário e alto; gerando informações sobre quais as áreas entre os dois municípios apresentam maior risco de sofrerem contaminação das águas subterrâneas.

Para a realização deste trabalho foram utilizados os bancos de dados cartográficos temáticos elaborado por Moreira (2002) e Moraes \& Lorandi (2009), na escala 1:50.000, organizado em ambiente de Sistema de Informações Geográficas - SIG, utilizando-se o software SPRING ${ }^{\circledR}$, versão 5.0.1 e dois métodos diferentes para o cruzamento dos dados: o Booleano e o Processo Analítico Hierárquico (AHP).

Os componentes e atributos do meio físico considerados, bem como os valores delimitadores das classes de susceptibilidade, estão demonstrados na tabela 1.

Análise booleana A análise booleana considera para cada variável um nível de evidência, cujas combinações desses níveis elaboram uma hipótese. As opera-

Tabela 1 - Relação entre os atributos e classes da carta de potencial à contaminação do manancial subterrâneo por vinhaça.

\begin{tabular}{|c|c|c|c|c|}
\hline \multirow{2}{*}{ Componentes } & \multirow{2}{*}{ Atributos } & \multicolumn{3}{|c|}{ Classes } \\
\hline & & Baixo & Intermediário & Alto \\
\hline \multirow{4}{*}{$\begin{array}{c}\text { Materiais } \\
\text { Inconsolidados }\end{array}$} & Textura & $\begin{array}{c}\text { Argilosa } \\
(\% \text { argila }>35)\end{array}$ & $\begin{array}{l}\text { Média/Argilosa } \\
(15<\% \text { argila }<35)\end{array}$ & $\begin{array}{c}\text { Arenosa } \\
(\% \operatorname{argila}<15)\end{array}$ \\
\hline & Permeabilidade & $<10^{-4} \mathrm{~cm} / \mathrm{s}$ & $10^{-4}-10^{-2} \mathrm{~cm} / \mathrm{s}$ & $>10^{-2} \mathrm{~cm} / \mathrm{s}$ \\
\hline & Mineralogia & $\begin{array}{c}\text { Montmorilonita, Alta \% } \\
\text { caolinita, CTC }>20\end{array}$ & $\begin{array}{c}\% \text { caolinita } 10-40 \% \\
\text { CTC } 5-20\end{array}$ & $\begin{array}{c}\% \text { caolinita }<10 \% \\
\text { CTC }<5\end{array}$ \\
\hline & Espessura & 3 & $3-7$ & $1-3$ \\
\hline \multirow[t]{2}{*}{$\begin{array}{l}\text { Substrato } \\
\text { Rochoso }\end{array}$} & Litologia & $\begin{array}{c}\text { Serra Geral } \\
\text { Intrusivas Básicas } \\
\text { Fm. Itaqueri }\end{array}$ & $\begin{array}{c}\text { Serra Geral } \\
\text { Intrusivas Básicas } \\
\text { Fm. Pirambóia (associados } \\
\text { a solos Litolíticos) }\end{array}$ & $\begin{array}{l}\text { Fm. Botucatu } \\
\text { Fm. Santa Rita } \\
\text { Quaternário }\end{array}$ \\
\hline & Profundidade (m) & $>15$ & $5-15$ & $<5$ \\
\hline \multirow{2}{*}{ Água } & Profundidade NA (m) & $>20$ & $7-20$ & $<7$ \\
\hline & Infiltração & Alta & Média/Argilosa & Baixa \\
\hline Relevo & Declividade & $>15$ & $5-15$ & $<5$ \\
\hline
\end{tabular}

Fonte: adaptado de Zuquette e Gandolfi (2004). 
ções booleanas ocorrem por meio de comparação ou lógica, sendo que neste caso, foram aplicados operadores lógicos (“AND”), a partir de imagens binárias, para o cruzamento dos mapas fazendo uma intersecção dos atributos no qual os cruzamentos foram realizados par a par (Tab. 2).

Segundo Leite (2005), o método booleano é de processamento rápido, simplificado e de fácil execução, porém limita o processo decisório à comparação de apenas dois critérios.

O mapa de uso do solo reclassificado foi utilizado como uma máscara para a seleção do potencial de contaminação de aquífero pela vinhaça, apenas nas áreas onde há cultivo de cana-de-açúcar ou solo exposto, visto que não se tem uma classificação mais apurada deste último tema em função da sazonalidade do plantio de cana-de-açúcar.

Tabela 2 - Cruzamentos com operador booleano lógico intersecção.

\begin{tabular}{l|l}
\hline Cruzamento & Resultado \\
\hline Alto com Alto & Alto \\
\hline Alto com Intermediário & Alto \\
\hline Alto com Baixo & Intermediário \\
\hline Intermediário com Alto & Alto \\
\hline Intermediário com Intermediário & Intermediário \\
\hline Intermediário com Baixo & Baixo \\
\hline Baixo com Alto & Intermediário \\
\hline Baixo com Intermediário & Baixo \\
\hline Baixo com Baixo & Baixo \\
\hline
\end{tabular}

Técnica de processo analítico hierárquico (AHP) Quando se têm diferentes fatores que contribuem para uma decisão e deseja-se verificar qual a contribuição relativa de cada um desses fatores, Saaty, citado por Câmara et al. (1996), propôs uma técnica de escolha baseada em comparação pareada, estabelecendo critérios de importâncias relativas ao relacionamento entre os fatores, em função de uma escala pré-estabelecida.

Em AHP decompõem-se hierarquicamente os atributos envolvidos em níveis sucessivos (Ehrlich s.d.) e estes são comparados aos pares, destacando que os julgamentos das comparações paritárias são baseados em experiência, intuição e também em dados físicos (PUC-Rio s.d.).

Para Saaty (1990 e 2003), a teoria reflete o método natural de funcionamento da mente humana, isto é, diante de um grande número de elementos (controláveis ou não), a mente os agrega em grupos segundo propriedades comuns. O cérebro repete esse processo e agrupa novamente os elementos em outro nível "mais elevado", em função de propriedades comuns existentes nos grupos de nível imediatamente abaixo. A repetição dessa sistemática atinge o nível máximo quando este representa o objetivo do nosso processo decisório. E, assim, é formada a hierarquia, por níveis estratificados.

Segundo Samizava et al. (2008), "o processo de ponderação pelo método AHP oferece a possibilidade de compensação de uma variável com a outra, por grau de importância relativa, o que torna possível a geração de novos cenários para um mesmo objetivo com a revisão e alteração da matriz de comparação pareada". Ainda, o mesmo autor comenta que a análise multicriterial utilizando AHP reduz a subjetividade, uma vez que esta está ligada ao conhecimento empírico do usuário ao atribuir valores de importância relativa entre as variáveis na matriz de comparação pareada.

Assim, para este trabalho, foi proposta a hierarquização e atribuição de critérios de comparação entre atributos apresentados na tabela 3.

Para a obtenção do produto cartográfico, que considera a influência relativa de cada atributo no resultado final, utilizou-se o software para AHP Expert Choice, versão Trial, para obtenção dos pesos relativos, visto que o SPRING ${ }^{\circledR}$ possui uma limitação ao operar apenas cinco atributos por vez. Ainda, com a ponderação de pesos acima descrita, obteve-se razão de consistência igual a 0.05 , valor abaixo de 0.10 , limite considerado na literatura para aceitação da matriz (Saaty apud Corseuil; Campos 2007).

Após a obtenção dos pesos relativos de cada atributo, foi realizada operação de álgebra de mapa utilizando a programação LEGAL do SPRING ${ }^{\circledR}$, na qual foi obtida a carta de potencial de contaminação do manancial subterrâneo por vinhaça aplicando AHP.

Lógica fuzzy A lógica fuzzy pode ser vista como uma generalização da lógica booleana convencional. A grande diferença entre as duas está no fato de a lógica fuzzy permitir certo grau de incerteza, isto é, ela aceita a noção de parcialmente verdadeiro ou parcialmente falso (Zimmermann 1987).

As operações de classificação contínua utilizam técnicas fundamentadas em noções de conjuntos nebulosos (fuzzy) para efetuar análises sobre os dados espaciais considerando suas variações transicionais, e elaborar documentos cartográficos com dados representados em formato numérico (Silva 2005).

Sui (1992) ressalta que a utilização da lógica $f u$ $z z y$ permite acrescentar detalhes de transição gradual, reduzindo assim a perda de informações relacionadas com as atividades de cada parcela analisada, possibilitando uma identificação mais analítica destas unidades.

De forma mais objetiva e preliminar, a lógica fuzzy pode ser definida como sendo uma ferramenta capaz de capturar informações vagas, em geral descritas em linguagem natural e convertê-las para um formato numérico, de fácil manipulação pelos computadores de 
Tabela 3 - Comparação pareada entre os atributos.

\begin{tabular}{|c|c|c|c|c|c|c|c|c|c|}
\hline & Perm & Text & Espes & ProfNA & Infilt & Litol & ProfSR & Decliv & Miner \\
\hline Perm & 1 & 2 & 3 & 4 & 5 & 6 & 7 & 8 & 9 \\
\hline Text & & 1 & 2 & 3 & 4 & 5 & 6 & 7 & 8 \\
\hline Espes & & & 1 & 2 & 3 & 4 & 5 & 6 & 7 \\
\hline ProfNA & & & & 1 & 2 & 3 & 4 & 5 & 6 \\
\hline Infilt & & & & & 1 & 2 & 3 & 4 & 5 \\
\hline Litol & & & & & & 1 & 2 & 3 & 4 \\
\hline ProfSub & & & & & & & 1 & 2 & 3 \\
\hline Decliv & & & & & & & & 1 & 2 \\
\hline Miner & & & & & & & & $1 / 2$ & 1 \\
\hline \multicolumn{5}{|c|}{$\begin{array}{l}\text { Perm = Permeabilidade; } \\
\text { Text = Textura; } \\
\text { Espes = Espessura; } \\
\text { ProfNA = Profundidade do Nível d'água; }\end{array}$} & \multicolumn{5}{|c|}{$\begin{array}{l}\text { Infilt = Infiltração; } \\
\text { Litol = Litologia; } \\
\text { ProfSR = Profundidade do substrato rochoso; } \\
\text { Decliv = Declividade; } \\
\text { Miner = Mineralogia. }\end{array}$} \\
\hline
\end{tabular}

Parâmetros para Comparação Pareada - Importância

\begin{tabular}{c|c|c|c|c}
\hline 1 & 3 & 5 & 7 & 9 \\
\hline Igual & Moderada & Essencial & Demonstrada & Extrema \\
\hline
\end{tabular}

2, 4, 6 e 8: valores intermediários entre julgamento

hoje em dia (Zadeh \& Jamshidi, 1997). Em outras palavras, estes correspondem a documentos em formato numérico, nos quais os atributos, fenômenos ou processo retratados apresentam distribuição contínua, o que permite caracterizar situações de gradação entre esses.

O conjunto fuzzy é uma generalização do conjunto ordinário. É definido a partir de um domínio contínuo, com graus de pertinência variando de 0 a 1 ou 0 a 255 , após a normalização. O processo de normalização é, na sua essência, idêntico ao processo introduzido pela lógica fuzzy, segundo a qual um conjunto de valores expressos numa dada escala é convertido em outro comparável, expresso em uma escala normalizada. Segundo Zadeh (1965), "a teoria do conjunto fuzzy é, em suma, o passo seguinte de aproximação entre a precisão da matemática clássica e a imprecisão do mundo real".

Para a normalização dos critérios, várias funções podem ser utilizadas e dentre as funções de pertinência ao conjunto fuzzy estão Sigmoidal, J-Shaped, Linear e User-Defined (Zadeh 1965, Eastman 1997, Ramos \& Mendes 2001). Em alguns sistemas de informações geográficas essa lógica já está implementada em rotinas computacionais denominadas módulos fuzzy.

Neste artigo a normalização em fuzzy foi realizada no software Idrisi 3.2 e as funções utilizadas foram linear para declividade e escoamento superficial e sigmoidal para os demais atributos. $\mathrm{O}$ uso destas funções baseou-se em Calijuri et al. (2002). Após esta nor- malização foi aplicada a técnica AHP com os mesmos pesos estipulados anteriormente.

RESULTADOS E DISCUSSÕES Todas as técnicas utilizadas resultaram em uma carta de potencial de contaminação do aquífero livre por vinhaça, utilizando-se como atributos físicos a textura, a permeabilidade, a mineralogia de argilominerais, a espessura, a litologia, a profundidade do substrato, a profundidade do nível d'água, a infiltração e a declividade.

Para a análise booleana foi produzida a carta apresentada na figura 3 e a distribuição espacial de classes observada na figura 5 .

Da técnica AHP foram obtidos os seguintes valores de pesos para os atributos: 0,274 para permeabilidade, 0,234 para textura, 0,189 para espessura, 0,105 para profundidade do nível d'água, 0,072 para infiltração, 0,049 para litologia, 0,034 para profundidade do substrato rochoso, 0,024 para declividade e 0,018 para mineralogia. Os produtos obtidos pela aplicação da técnica AHP podem ser observados na figura 4 e na figura 6 , que representa a distribuição de áreas de acordo com as classes de potencial de contaminação.

Para a lógica fuzzy foi produzida a carta apresentada na figura 7 e a distribuição espacial de classes observada na figura 8 . Nesta carta foi aplicada a normalização e posteriormente aplicada 


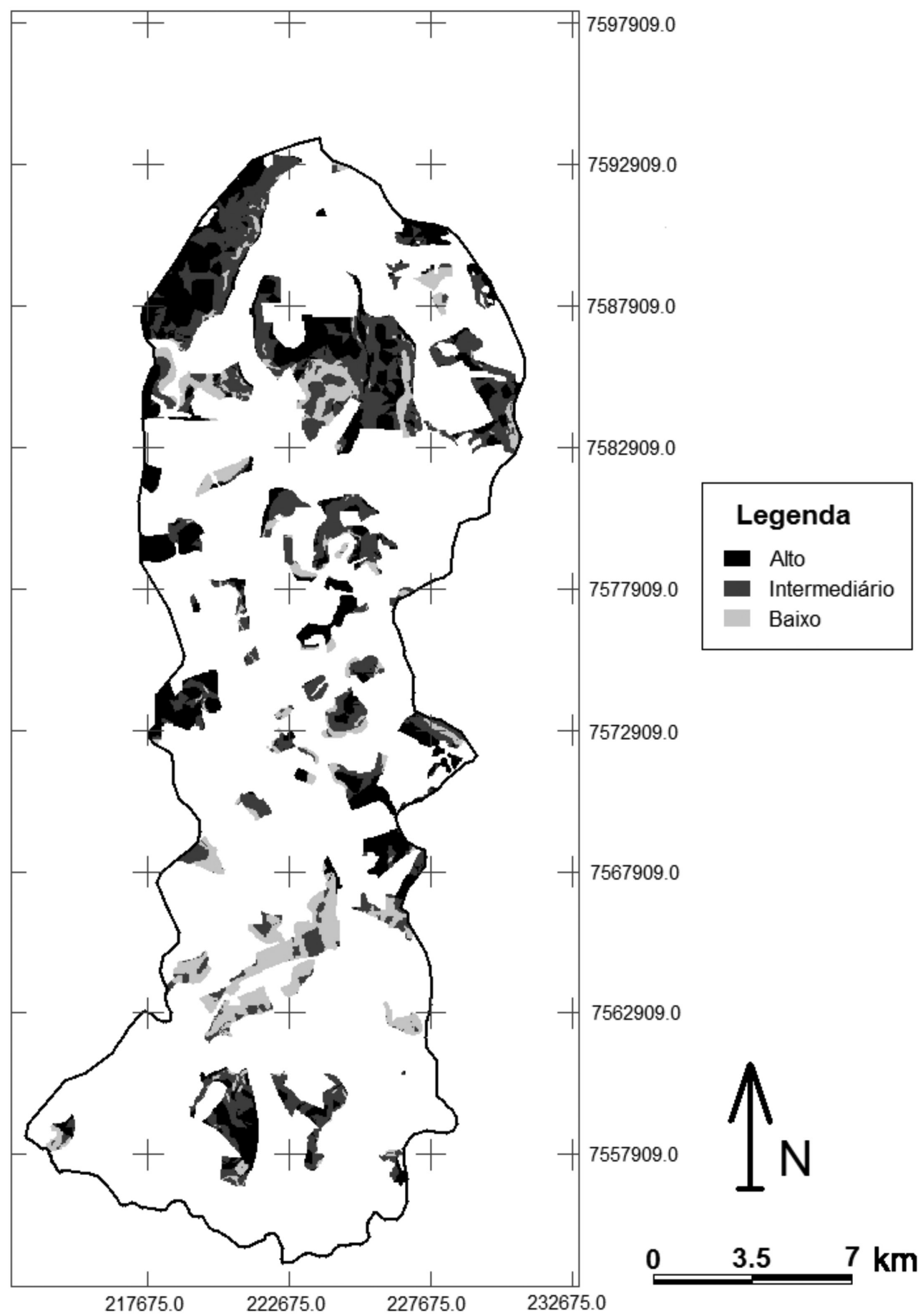

Figura 3 - Resultado da análise Booleana.

a técnica AHP com os mesmo valores de pesos da etapa anterior.

Em função dos resultados obtidos pela aplicação das técnicas acima citadas observa-se que o resultado da técnica fuzzy é a mais restritiva, seguida da AHP e análise Booleana, visto que a porcentagem do tema alto é maior $(75 \%>72 \%>35 \%)$ e no tema baixo é menor as outras técnicas $(7 \%<13 \%<22 \%)$. Ainda da observação da figura 4 verifica-se que a maioria das áreas atualmente usadas para o cultivo de cana-de-açúcar ou solo exposto, sujeitas à utiliza- ção de vinhaça para fertirrigação, situa-se em regiões de alto risco de contaminação do aquífero livre.

CONCLUSÕES O trabalho, embora focado nas áreas de cana-de-açúcar e solo exposto, possibilita um melhor ordenamento territorial para as demais áreas da bacia visando à precaução de contaminação do aquífero livre em áreas de mudança de cultura, visto que a análise deste trabalho contemplou toda a área da BHRP. Ainda, fornece subsídios para uma pré-análise de um plano de ordenamento do território rural para estabelecimento da 


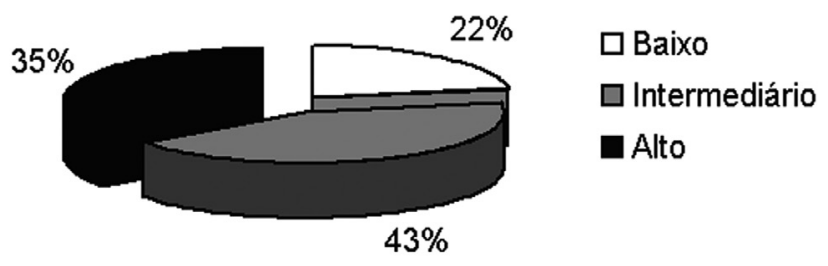

Figura 4 - Resultado da análise Booleana em porcentagem. cultura de cana-de-açúcar e uso da fertirrigação com vinhaça.

No aspecto do método AHP, o grau de inconsistência encontrado indica a consistência da matriz, não necessariamente a aderência à realidade. Porém, é importante um conhecimento empírico do usuário de forma que subsidie a atribuição dos pesos relativos entre as variáveis, o que determina a aderência do método mais próximo possível à realidade.

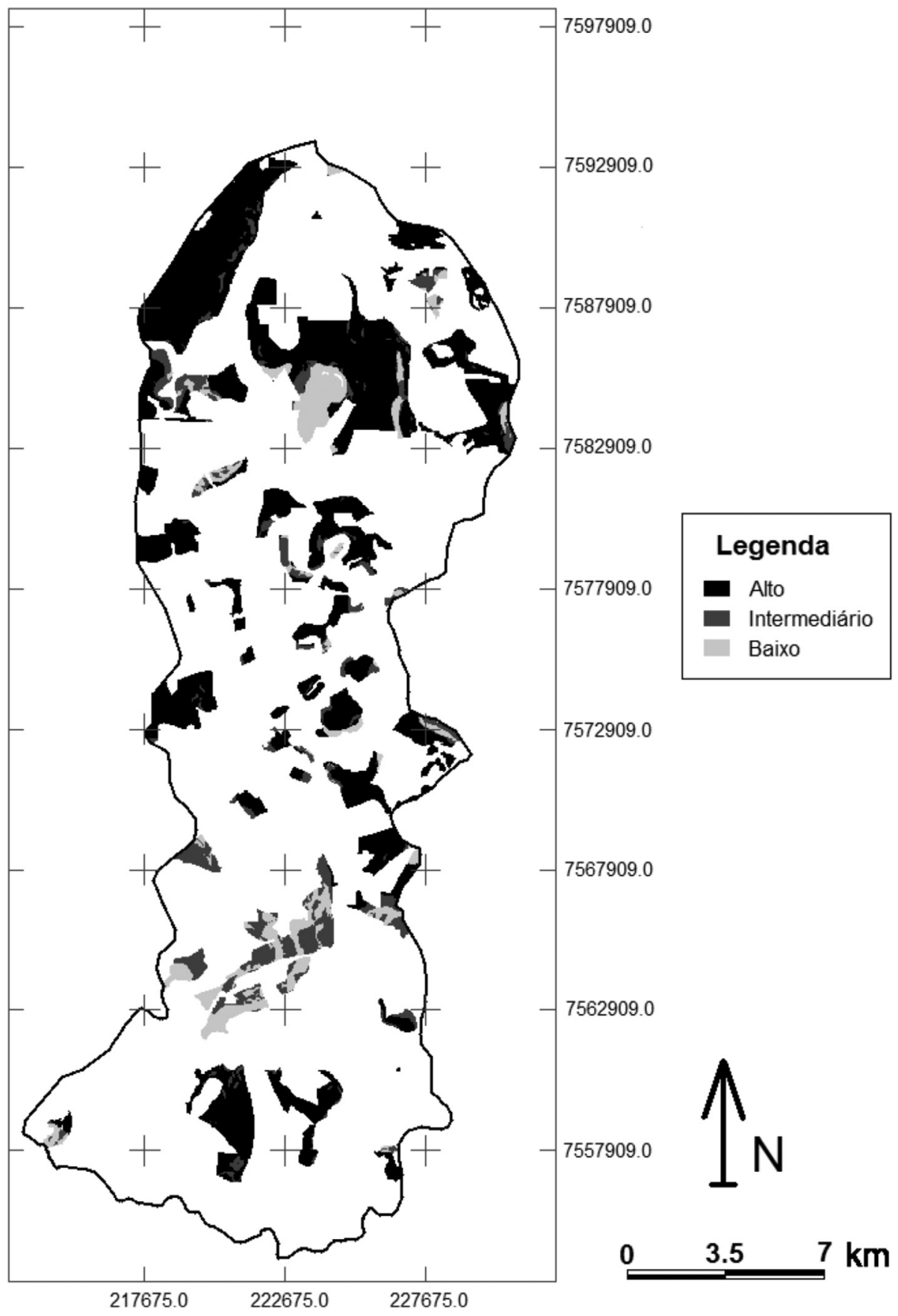

Figura 5 - Resultado da AHP. 


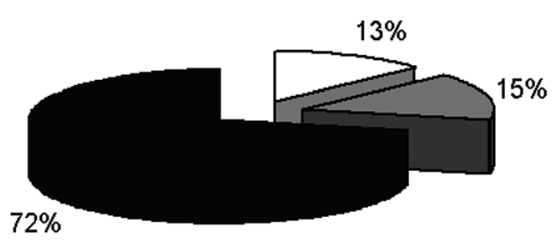

Figura 6 - Resultado da AHP em porcentagem.

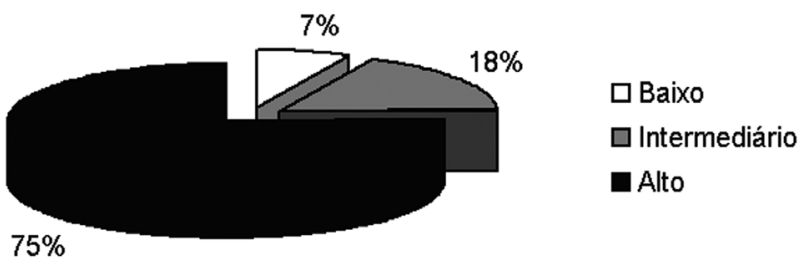

Figura 8 - Resultado da Fuzzy - AHP em porcentagem.

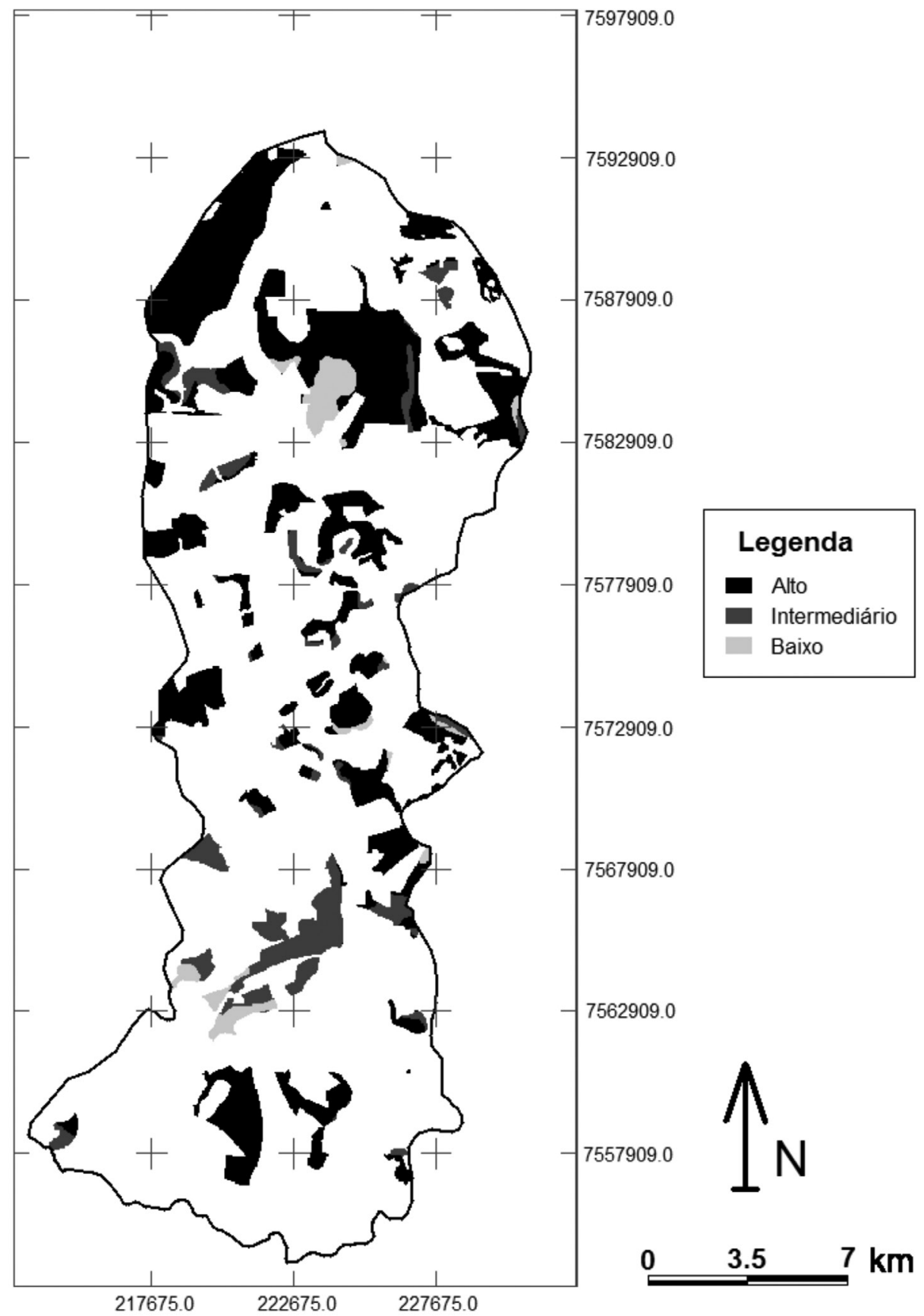

Figura 7 - Resultado da Fuzzy - AHP. 
Ao comparar esta técnica com a análise Booleana, foi observado que a técnica AHP se mostrou mais conservadora, entretanto este parecer está intrinsecamente ligado ao grau de conhecimento dos especialistas do meio físico.

Há, porém, uma crítica quanto a estas duas técnicas, pois elas consideram a região de fronteira como um limite rígido.

Já a lógica fuzzy permitiu a obtenção de resultados que representam de forma mais adequada o comportamento de distribuição espacial destes atributos e aspectos. Pois nela é clara que a região de fronteira é nebulosa da mesma forma que os atributos analisados se comportam na natureza.

No que se refere à representação espacial de uni- dades constituintes de um compartimento do meio, verificou-se que a técnica fuzzy permite caracterizar e representar diferentes relações de transição que uma unidade possa apresentar com as adjacentes. Este aspecto possibilita não apenas informar sobre a distribuição espacial de atributo, mas no contexto do processo de obtenção de informações derivada e/ou interpretativas informa que as regiões de transição, em função da intensidade e peso de influência de cada atributo, podem caracterizar áreas que possam vir a merecer análise mais cuidadosa, pois podem caracterizar regiões com aspectos de potencialidades diferentes do restante da unidade, como nos casos de unidades com contatos complexos, ou de unidades com pesos de influência diferenciados.

\section{Referências}

Brasil. Empresa Brasileira de Pesquisa Agropecuária. Centro Nacional de Pesquisa de Solo. 1999. Sistema brasileiro de classificação de solos. Brasília: EMBRAPA Produção de Informação; Rio de Janeiro: Embrapa Solos, 412 p.

Brasil. Ministério da Agricultura, Pecuária e Abastecimento. 2007. Balanço da Cana-de-Açúcar e Agroenergia Nacional. MAPA/SPAE, Brasília, 140 p.

Brasil. Ministério do Meio Ambiente. Conselho Nacional do Meio Ambiente. 2005. Resolução 357. Dispõe sobre a classificação dos corpos de água e diretrizes ambientais para o seu enquadramento, bem como estabelece as condições e padrões de lançamento de efluentes, e dá outras providências. Disponível em http://www.mma. gov.br/port/conama/res/res05/res35705.pdf. Acessado em: 22 set 2008.

Brito F.L. \& Rolim M.M. 2005. Comportamento do efluente do solo fertirrigado com vinhaça. Agropecuária Técnica, 26(1):60-67. Disponível em http://www.cca.ufpb.br/ revista/pdf/2005_1_9.pdf. Acessado em 27 set 2008.

Calijuri M.L., Melo A.L.O., Lorentz J.F. 2002. Identificação de áreas para implantação de aterros sanitários com uso de análise estratégica de decisão. Informática Pública, 4(2): 231-250.

Câmara G., Souza R.C.M., Freitas U.M., Garrido J. 1996. SPRING: Integrating remote sensing and GIS by objectoriented data modeling. Computers \& Graphics, 20:(3) 395-403.

Casarini D.C.P. 2008. Pesquisa vai avaliar impacto da indústria sucroalcooleira sobre os recursos hídricos. Portal do Governo do Estado de São Paulo. Disponível em: http://www.saopaulo.sp.gov.br/sis/lenoticia. php?id=93442\&c=6. Acessado em 22 set 2008.

Courseuil C.W. \& Campos S. 2007. Análise de adequação do uso das terras por meio de técnicas de geoprocessamento e de análise de multicritérios. In: INPE, Simpósio Brasileiro de Sensoriamento Remoto, 13, Florianópolis, Atas, p. 2471-2478.

Cruz R.L. 1991. Efeito da aplicação de vinhaça sobre o solo e água subterrânea. São Carlos, Tese de Doutoramento, Escola de Engenharia, Universidade de São Paulo, 121p.

Cunha R.C. de A., Costa A.C.S. da, Maset B., Casarini D.C.P. 1981. Effects of irrigation with vinasse and dynamics of its constituents in the soil: physical and chemical aspects. Water Science Technology, 19(8):155-165.

Eastman J.R. 1997. IDRISI for Windows: User's Guide. Version 3.2. Worcester: Clark University - Graduate School of Geography.

Ehrlich P.J. 2008. Decisões com Múltiplos Objetivos. s.d. Disponível em http://www.fgvsp.br/academico/ professores/Pierre_J_Ehrlich/. Acessado em 25 nov 2008.

Guagnoni W.C., Nakao S.H., Ribeiro M. S. 2003. Decisões de Investimento e Meio Ambiente no Setor Sucroalcooleiro. In: International Conference of the Iberoamericam Academy of Management, São Paulo, 3, Atas. Disponível em http://www.fgvsp.br/iberoamerican/Papers/0341 Artigo-decisoes-investimento-ambiental-06.pdf. Acessado em 22 set 2008.

Leite N.B.F. 2005. Associação da Análise Booleana e Lógica Fuzzy ao sistema de informação geográfica aplicados a planos diretores. Estudo de Caso: Ponte Nova, MG. Viçosa, Tese de doutoramento, Universidade Federal de Viçosa.

Lyra M.R.C.C., Rolim M.M., Silva J.A.A. 2003. Toposseqüência de solos fertigados com vinhaça: contribuição para a qualidade das águas do lençol freático. Engenharia Agrícola e Ambiental, Campina Grande, 7(3):525-532.

Mendonça F., Danni-Oliveira I.M. 2007. Climatologia: noções básicas e climas do Brasil. São Paulo: Oficina de Textos, 206p.

MINISTÉRIO DO INTERIOR. Portaria/GM $n^{\circ} 323$, de 29 de novembro de 1978. Disponível em: <www.ipef.br/ legislacao/bdlegislacao/arquivos/272.rtf $>$. Acesso em: 22 set 2008.

MINISTÉRIO DO INTERIOR. Portaria $n^{\circ} 158$, de 03 de novembro de 1980. Disponível em: <www.ipef.br/ legislacao/bdlegislacao/arquivos/272.rtf $>$. Acesso em: 22 set 2008.

Moraes M.E.B. \& Lorandi R. 2009. Análise dos elementos da paisagem na bacia hidrográfica do Ribeirão do Pântano (SP) como subsídio ao zoneamento ambiental. Geografia, Rio Claro, 34(3):577-594.

Moreira M.A.A. 2002. Procedimentos geológico- 
geotécnicos para seleção de áreas para a disposição de resíduos sólidos domésticos em aterro no município de Descalvado (SP). São Carlos. Dissertação de Mestrado. Universidade Federal de São Carlos, 165 p.

PUC-Rio. s.d. O Método AHP - Analytic Hierarchy Process. Disponível em http://www.maxwell.lambda. ele.puc-rio.br/cgi-bin/PRG_0599.EXE/10385_4.PDF? NrOcoSis $=33319 \&$ CdLinPrg $=p t$. Acessado em 25 nov 2008.

Ramos R.A.R. \& Mendes J.F.G. 2001. Avaliação da aptidão do solo para localização industrial: o caso de Valença. Revista Engenharia Civil, Universidade do Minho, Minho, Portugal, 10:7-29.

Ribas M.M.F., Sousa L.B., Sousa A.P., Freitas P.S.L. 2008. Tratamento Anaeróbio de Vinhaça de Cana-de-açúcar em Reator de Fluxo Pistonado Preenchido com Pedras de Calcário: Estudo Preliminar. In: International Symposium on Sanitary and Environmental Engineering, SIDISA 08, Florence, Itália. Modelling and automation of water and wastewater treatment process.

Ribas M.M.F., Sousa L.B., Sousa A.P., Freitas P.S.L. 2008. Tratamento Anaeróbio de Vinhaça de Cana-de-açúcar em Reator de Fluxo Pistonado Preenchido com Pedras de Calcário: Estudo Preliminar. In: International Symposium on Sanitary and Environmental Engineering, SIDISA 08, Florence, Itália, Proceedings, CD-Rom.

Ross J.L.S. \& Moroz I.C. 1997. Mapa Geomorfológico do Estado de São Paulo. Laboratório Geomorfologia Depto. Geografia - FFLCH-USP. 2v, 64p., 2 mapas color, Escala 1:500.000.

Rossetto A.J. 1987. Utilização agronômica dos subprodutos e resíduos da indústria açucareira e alcooleira. In: Paranhos S.B. (coord.) Cana-de-açúcar: cultivo e utilização. São Paulo: Fundação Cargill, 2:435-504.

Saaty T.L. 1990. How to make a decision: the analytic hierarchy process. European Journal of Operational Research, North-Holland, 48:9-26.

Saaty T.L. 2003. Decision-making with the AHP: why is the principal eigenvector necessary. European Journal of
Operational Research, North-Holland, 145:85-91.

Samizava T.M., Kaida R.H., Imai N.N., Nunes J.O.R. 2008. SIG aplicado à escolha de áreas potenciais para instalação de aterros sanitários no município de Presidente Prudente - SP. Revista Brasileira de Cartografia, 60:43-55.

São Paulo. Companhia de Tecnologia de Saneamento Ambiental. Secretaria de Estado do Meio Ambiente. 2006. Norma Técnica P4.231. Vinhaça - critérios e procedimentos para aplicação no solo agrícola. Disponível em http://www.ana.gov.br/SalaImprensa/ doc_oficina/Vinhaça.pdf. Acessado em 22 set 2008.

Silva M.A.S., Griebeler N.P., Borges L.C. 2007. Uso de vinhaça e impactos nas propriedades do solo e lençol freático. Engenharia Agrícola e Ambiental, Campina Grande, 11(1):108-114.

Silva S.F. 2005. Zoneamento geoambiental com auxílio de lógica fuzzy e proposta de um geoindicador para caracterização do meio físico da bacia do rio do Peixe. São Carlos, Tese de doutoramento em geotecnia, Universidade de São Paulo (USP), Escola de Engenharia de São Carlos (EESC), 441p.

Sui D.Z. 1992. A Fuzzy GIS Modeling Approach for Urban Land Evolution. Computer Environment and Urban Systems, 16(2):101-115.

Vieira D.B. 1986. Fertirrigação sistemática da cana-de-açúcar com vinhaça. Álcool e Açúcar, São Paulo, 28:26-30.

Zadeh L.A \& Jamshidi 1997. Aplications of Fuzzy Logic: Towards High Machine Inteligence Quotient Systems. Series on Environmental and Intelligent Manufacturing. Prentice Hall, 448 p.

Zadeh L.A. 1965. Fuzzy sets. Information and control, 8:338-353.

Zimmermann H.J. 1987. Fuzzy sets, decision making, and expert systems. Boston, Kluwer Academic Publishers. $335 \mathrm{p}$.

Manuscrito ID 13487

Submetido em 19 de fevereiro de 2009 Aceito em 18 de agosto de 2009 